\title{
A diagnostic test for malnutrition in adults: mid-upper arm circumference towards body mass index: A literature review
}

Received 15 January 2021 Accepted 13 July 2021

Link to DOI:

10.25220/WNJ.V04.i2.0012

Journal Website: www.worldnutrijournal.org

\author{
Fathiyyatul Khaira ${ }^{1,2}$, Fiastuti Witjaksono ${ }^{1}$, Diyah Eka Andayani ${ }^{1}$ \\ 1. Department of Nutrition, Faculty of Medicine, Universitas Indonesia-Dr. Cipto Mangunkusumo \\ General Hospital, Jakarta, Indonesia \\ 2. Department of Nutritional Sciences, Faculty of Medicine, Universitas Andalas, Padang, \\ Indonesia
}

\begin{abstract}
Body mass index is commonly used for detecting malnutrition. At certain conditions, body mass index cannot be measured, so mid-upper arm circumference can be an alternative measurement for detecting malnutrition. Several studies have proposed the cut-off point of mid-upper arm circumference in adults along with its sensitivity, specificity, and area under the ROC curve (AUC). This article aims to describe the diagnostic test for malnutrition using the upper arm circumference in adults and summarize the results of the related studies.
\end{abstract}

Keywords BMI, diagnostic test, malnutrition, MUAC

\section{Introduction}

Nutritional status is defined as a body condition that is the result of a balance of intake, absorption, use of nutrients that can affect physiological and pathological conditions. ${ }^{1}$ If for any reason, such as insufficient intake, increased demand for nutrients, or a disorder in the absorption/use of nutrients, there is a negative balance, then undernutrition/malnutrition develops. ${ }^{2}$ Malnutrition is assessed based on an assessment of food intake, laboratory tests, anthropometric measurements, and clinical observation. Anthropometric measurements involve measuring physical dimensions and body composition, the results can be vary depending on age, sex, race, and nutritional status. This measurement is often used to assess energy and protein imbalances, as well as to assess the degree of

\section{Corresponding author:}

Fathiyyatul Khaira

Department of Nutrition, Faculty of Medicine, Universitas

Indonesia

Jl. Salemba Raya no.6, Central Jakarta, Indonesia

Email:fathiyyatul.khaira@gmail.com malnutrition, but cannot explain a specific nutrient deficiency. ${ }^{3}$ Some anthropometric measurement methods used to assess nutritional status are body mass index (BMI) and mid-upper arm circumference (MUAC). In certain conditions, it can be difficult to perform height and weight measurements to calculate BMI. ${ }^{4}$ Mid-upper arm circumference can be an alternative measurement for undernutrition screening. To date, there was no valid cut-off point for mid-upper arm circumference in adults as in children. This article aims to describe the diagnostic test for malnutrition using the mid-upper arm circumference in adults and summarize the results of the related studies.

\section{Body mass index}

Body mass index was first described by Adolph Quetelet in 1835, so it is also called the Quetelet index. ${ }^{5} \mathrm{BMI}$ is defined as body weight in kilograms divided by the square of height in meters. ${ }^{3,5}$ It is a commonly used measurement for assessing nutritional status quickly, easily, and noninvasively. ${ }^{3}$ 
The body mass index has some limitations, it cannot differentiate between body weight due to fat mass or fat-free mass. BMI values can be high due to excess fat mass, muscle mass (for example in athletes), or edema. ${ }^{1,3}$ In certain circumstances, BMI is difficult to assess, for example, if the patient is unable to stand or conditions that affect height measurements such as kyphosis, compression fractures vertebral due to osteoporosis, or scoliosis. ${ }^{6}$ The World Health Organization (WHO) established the BMI cut-off value for assessing nutritional status by relating it to morbidity and mortality. BMI $<18.5$ $\mathrm{kg} / \mathrm{m}^{2}$ is categorized as undernutrition/malnutrition.

\section{Mid-upper arm circumference}

The measurement of the MUAC is made at the midpoint between the acromion and olecranon. MUAC is consist of subcutaneous fat and muscle, so any changes in MUAC can represent changes in muscle mass, subcutaneous fat mass, or both. In malnourished patients who tend to have low subcutaneous fat, changes in MUAC are more representative of changes in muscle mass. Measuring MUAC is easy, fast, and only uses a simple tool (measuring tape). ${ }^{3}$ MUAC measurement can be performed in patients who cannot stand because it can be taken in a lying position. There was no significant difference between measurements of upper arm circumference in standing and lying positions $(p$-value $=0.855){ }^{7}$

In the measurement in a standing position, the subject stands with feet together and arms bent 90 degrees at the elbows with palms facing up. The examiner stands behind the subject and looks for the acromion process of the scapula. Then the examiner holds the end of the measuring tape at the acromion and pulls it up to the olecranon. After that, the examiner holds the measuring tape in that position and marks the midpoint between the acromion and olecranon. Subjects were asked to straighten their hands then the measuring tape was looped on the marked point and measured in the nearest millimeter. ${ }^{8}$ For more details see Figure 1.

Several studies have been conducted to assess the usefulness of measuring the MUAC. ${ }^{9-12}$ McMillan et al. $^{9}$ assessed the influence of several variables (BMI, weight loss, skinfold thickness, MUAC, albumin, C-reactive protein, and cancer type and stage) on Karnofsky performance status in 148 advanced gastrointestinal cancer patients. From multiple regression analyzes, only MUAC and $\log _{10}$ C-reactive protein $\left(\mathrm{R}^{2}=0.462, \mathrm{P}<0.0001\right)$ in men and only MUAC and weight loss in women $\left(\mathrm{R}^{2}=\right.$ $0.485, \mathrm{P}<0.01)$ as an independent predictor of Karnofsky performance status. ${ }^{9}$

MUAC is inversely related to the risk of all-cause mortality. ${ }^{10,11}$ Higher MUAC with normal BMI has a low risk of mortality. ${ }^{10}$ Whereas low MUAC has a statistically significant relationship with increased risk of mortality in the elderly that is stronger than with low BMI and calf circumference. ${ }^{12}$

\section{A diagnostic test for malnutrition}

Assessing the validity of screening tools is one of the goals of diagnostic tests. Besides, diagnostic tests also aim to establish a diagnosis of disease, for patient treatment, and epidemiological studies. The basic principle of a diagnostic test is to find a new diagnostic test that has several advantages over the previous diagnostic test. Some of them are that the diagnostic value is not much different, it is not invasive, easier to use, and cheaper. ${ }^{13}$

The validity of an instrument with a nominal scale can be assessed by comparing it with the best available diagnostic tool (gold standard). BMI is used as the gold standard in this diagnostic test. MUAC meets the basic principle of a diagnostic test because MUAC does not require expensive equipment, easy to perform, and not invasive. MUAC can be used to assess nutritional status if MUAC has high sensitivity (a slight possibility for false negative) and fair specificity. ${ }^{13}$ Information obtained from the diagnostic test of MUAC towards BMI is presented in Table 1.

\section{Receiver operating characteristic (ROC) curve of MUAC towards BMI}

The receiver operating characteristic (ROC) curve is a graph that presents the bargaining between sensitivity and specificity to determine the cut-off point of MUAC towards BMI. ${ }^{13}$ The $\mathrm{Y}$ coordinate is the sensitivity against the false positive (1specificity) value as the $\mathrm{X}$ coordinate. The cut-off point of MUAC is determined based on the highest 
sensitivity and specificity or the highest Youden's index (sensitivity + specificity -1$){ }^{15}$

Diagnostic test performance can be assessed by calculating the area under the ROC curve (AUC). An AUC values range from 0 to 1 , the closer to number 1 the better the diagnostic test. An AUC value equal to 1 represents a perfect diagnostic test, which is very accurate in distinguishing between malnutrition or not. ${ }^{15,16}$ The categories used to summarize accuracy of AUC in ROC analysis were as follows: AUC of 0.9-1 (excellent), 0.8-0.9 (good), 0.7-0.8 (fair), 0.6-0.7 (poor) and 0.5-0.6 (fail). A test with an AUC $\geq 0.85$ is generally considered as an accurate test. ${ }^{17}$

\section{Research about MUAC cut-off point for detecting} malnutrition

Various studies have shown a significant correlation between MUAC and BMI, it is known that individuals with low MUAC are likely to have a low BMI. ${ }^{4,6,18-23}$ Research conducted by Brito et al. ${ }^{8}$ on 1373 inpatients at a hospital in Spain, showed that there was a correlation between BMI and MUAC with $r=0.78(p<0.001)$. The cut-off point value for detecting malnutrition obtained from this study was $22.5 \mathrm{~cm}$ for both men and women. This study also obtained a regression equation to find BMI, that is $0.042+0.873 \times$ MUAC $(\mathrm{cm})\left(\mathrm{R}^{2}=0.609\right)$. Tuck and Henessy ${ }^{19}$ also developed a regression equation to determine the BMI from MUAC. For males: BMI = $1.01 \mathrm{x}$ upper arm circumference - $4.7\left(\mathrm{R}^{2}=0.76\right)$ and for women: $\mathrm{BMI}=1.10 \mathrm{x}$ upper arm circumference - $6.7\left(R^{2}=0.76\right) .{ }^{19}$ This equation has been validated in the study of Barosa et al. ${ }^{24}$

Food and Nutrition Technical Assistance III Project (FANTA) conducted a meta-analysis regarding the sensitivity and specificity of various cut-off points for MUAC in adults (men and women who were not pregnant) to identify malnutrition measured by BMI $<18.5 \mathrm{~kg} / \mathrm{m}^{2}$. This study suggested that MUAC in the range of $\leq 23.0$ to $\leq 25.5$ $\mathrm{cm}$ can be used as an indicator of low BMI (BMI $<18.5 \mathrm{~kg} / \mathrm{m}^{2}$ ), with acceptable sensitivity and specificity values. The cut-off point of MUAC $\leq 24.0$ $\mathrm{cm}$ was chosen for reasons of optimal sensitivity and specificity. ${ }^{4}$

Several proposed cut-off points of MUAC for detecting malnutrition along with its sensitivity, specificity, and AUC was summarized in Table 2. The cut-off point of MUAC may be varied due to differences in body composition among different races, especially the distribution of body fat, which may be not adequately captured by measures of overall adiposities (BMI) when compared to MUAC, which measures regional adiposity. The higher cut-off point might be more accurate in Asian populations that have a higher proportion of body fat than other races (e.g., Caucasians and Africans). ${ }^{25}$ Overall, the sensitivity, specificity, and AUC of MUAC towards BMI is good enough, so MUAC can be used for detecting malnutrition.

\section{Conclusion}

Since the sensitivity, specificity, and AUC of MUAC is good, it can be an alternative measurement for detecting malnutrition in adults, particularly in a community setting or low-resource setting. It can also be used in a hospital setting when BMI cannot be measured. There was no valid cutoff point of MUAC that can be used in all population. populations. Further research needs to validate this cut-off point. 
a.

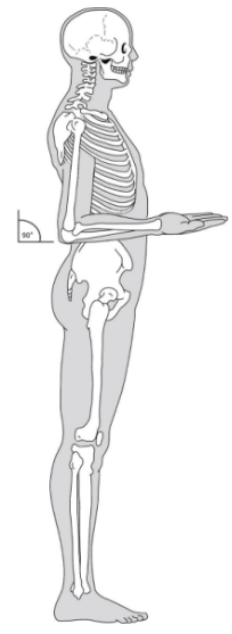

b.

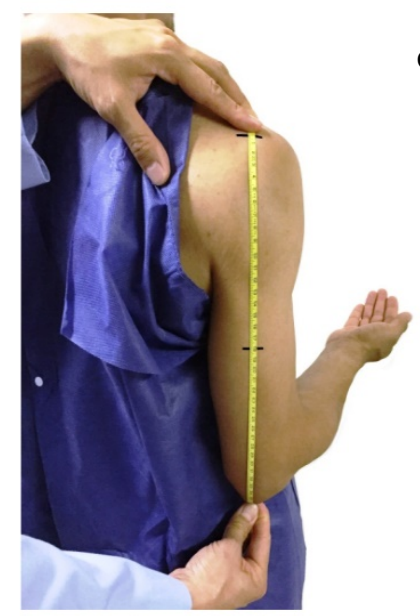

c.

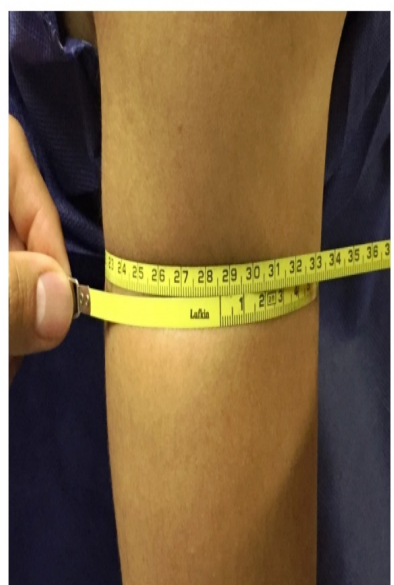

Figure 1. MUAC measurement in a standing position

a. Standing position of the subject b. Position the tape correctly and mark the midpoint of the upper arm. c. Measure the circumference of the mid-upper arm

Source: reference number 8

Table 1. 2x2 table for MUAC and BMI

\begin{tabular}{ccccc}
\hline & & \multicolumn{2}{c}{ Malnutrition (measured by BMI) } & \multirow{2}{*}{ Total } \\
\cline { 3 - 4 } & & BMI $<18.5 \mathrm{~kg} / \mathrm{m}^{2}$ & BMI $\geq 18.5 \mathrm{~kg} / \mathrm{m}^{2}$ & \\
\hline \multirow{2}{*}{ MUAC } & $<$ cut-off point & True positive (a) & False positive (b) & $\mathrm{a}+\mathrm{b}$ \\
& $\geq$ cut-off point & False negative (c) & True negative (d) & $\mathrm{c}+\mathrm{d}$ \\
& Total & $\mathrm{a}+\mathrm{c}$ & $\mathrm{b}+\mathrm{d}$ & $\mathrm{a}+\mathrm{b}+\mathrm{c}+\mathrm{d}$
\end{tabular}

From the table above can be assessed sensitivity, specificity, positive predictive value, and negative predictive value:

a. $\quad$ Sensitivity $=a /(a+c)$.

b. $\quad$ Specificity $=d /(b+d)$.

c. Positive predictive value $=\mathrm{a} /(\mathrm{a}+\mathrm{b})$.

d. Negative predictive value $=\mathrm{d} /(\mathrm{c}+\mathrm{d}){ }^{4,14}$ 
Table 2. The cut-off point of MUAC from various studies for detecting malnutrition

\begin{tabular}{|c|c|c|c|c|c|c|}
\hline Researcher & Subject & Total subject & $\begin{array}{l}\text { MUAC cut-off } \\
\text { point }(\mathrm{cm})\end{array}$ & Sen & Sp & AUC \\
\hline Brito et al. $^{6}$ & Inpatient, Spain & 1373 subjects & 22.5 & 67.7 & 94.5 & 0.92 \\
\hline \multirow{2}{*}{$\begin{array}{c}\text { van Tonder et } \\
\text { al. }^{18}\end{array}$} & \multirow{2}{*}{$\begin{array}{c}\text { Inpatient, South } \\
\text { Africa }\end{array}$} & 86 males & 23.7 & 86.4 & 78.6 & 0.88 \\
\hline & & 80 females & 23.5 & 93.1 & 100 & 0.98 \\
\hline \multirow{2}{*}{$\begin{array}{l}\text { Goswami et } \\
\text { al. }^{20}\end{array}$} & \multirow[t]{2}{*}{ Elderly, India } & 267 males & 25.7 & 80.2 & 78.6 & 0.85 \\
\hline & & 259 females & 24.3 & 79 & 79 & 0.86 \\
\hline \multirow[t]{2}{*}{ Das et al. ${ }^{22}$} & \multirow{2}{*}{$\begin{array}{l}\text { Adults slum } \\
\text { dwellers, India }\end{array}$} & 467 males & 22.7 & 85.71 & 74.8 & 0.85 \\
\hline & & 488 females & 21.9 & 91.67 & 79.89 & 0.93 \\
\hline \multirow[t]{2}{*}{ Sultana et al. ${ }^{21}$} & \multirow{2}{*}{$\begin{array}{l}\text { Inpatient, } \\
\text { Bangladesh }\end{array}$} & 260 males & 25.1 & 92.6 & 79.4 & 0.814 \\
\hline & & 390 females & 23.9 & 92.6 & 76.6 & 0.882 \\
\hline Thorup et al. ${ }^{23}$ & $\begin{array}{c}\text { Urban public } \\
\text { hospitals, Nepal }\end{array}$ & 302 subjects & 24.5 & 92.86 & 82.48 & 0.94 \\
\hline FANTA-III $^{4}$ & $\begin{array}{l}\text { A meta-analysis } \\
\text { from } 17 \text { studies } \\
\text { with various } \\
\text { population }\end{array}$ & - & 24 & 81.9 & 85.6 & _ \\
\hline
\end{tabular}

\section{Conflict of Interest}

Authors declared no conflict of interest regarding this article.

\section{Open Access}

This article is distributed under the terms of the Creative Commons Attribution 4.0 International Licence

(http://creativecommons.org/licenses/by/4.0/), which permits unrestricted use, distribution, and reproduction in any medium, provided you give appropriate credit to the original author(s) and the source, provide a link to the Creative Commons license, and indicate if changes were made.

\section{References}

1. Andreoli A, Garaci F, Pio F, Guglielmi G. Body composition in clinical practice. Eur $\mathrm{J}$ Radiol. 2016;85:1461-8.

2. Correia MITD. Nutrition screening vs nutrition assessment: What's the difference? Nutr Clin Pract. 2018;33(1):62-72.

3. Gibson RS. Principles of Nutritional Assessment. New York: Oxford University Press; 2005. p. 252-91.

4. Tang AM, Chung M, Dong K, Wanke C, Bahwere P, Bose $\mathrm{K}$, et al. Determining a global mid-upper arm circumference cutoff to assess underweight in adults (men and nonpregnant women). Washington; 2017.

5. Jiménez EG. Body composition: Assessment and clinical value. Endocrino Nutr. 2013;60(2):69-75.

6. Brito NB, Llanos JPS, Ferrer MF, García JGO, Brito I, Castro FP-G, et al. Relationship between mid-upper arm circumference and body mass index in inpatients. PLoS One. 2016;11(8):e0160480.

7. Jensen TG, Dudrick SJ, Johnston DA. A comparison of triceps skinfold and upper arm circumference 
measurements taken in standard and supine Positions. $\mathbf{J}$ Parenter Enter Nutr. 1981;5(6):519-21.

8. Centers for Disease Control and Prevention. National Health and Nutrition Examination Survey: Anthropometry Procedures Manual. [Internet]. 2017. Available from:

https://wwwn.cdc.gov/nchs/data/nhanes/20172018/manuals/2017_Anthropometry_Procedures_Man ual.pdf

9. Mcmillan DC, Forrest LM, Gorman PO, Angerson WJ, Mcardle CS. Performance status of male and female advanced cancer patients is independently predicted by mid-upper arm circumference measurement. 2009;42(2):191-3.

10. Wu L, Lin Y, Kao T, Lin C, Wang C, Wang C, et al. Mid-arm circumference and all-cause, cardiovascular, and cancer mortality among obese and non-obese US adults : the National Health and Nutrition Examination Survey III. Sci Rep. 2017;7(1):2302.

11. Weng C, Tien C, Li C, Heureux AL, Liu C, Lin C, et al. Mid-upper arm circumference, calf circumference and mortality in Chinese long-term care facility residents : a prospective cohort study. BMJ Open. 2018;8(5):e020485.

12. Wijnhoven HAH, van Bokhorst-de van der Schueren MAE, Heymans MW, de Vet Henrica CW, Kruizenga HM, Twisk JW, et al. Low mid-upper arm circumference, calf circumference, and body mass index and mortality in older persons. Journals Gerontol A Biol Sci Med Sci. 2010;65 A(10):1107-14.

13. Sastroasmoro S, Ismael S. Dasar-dasar Metodologi Penelitian Klinis. 4th ed. Jakarta: Sagung Seto; 2011. 219-361 p.

14. Parikh R, Mathai A, Parikh S, Chandra Sekhar G, Thomas R. Understanding and using sensitivity, specificity, and predictive values. Indian J Ophthalmol. 2008;56(1):45-50.

15. Bewick V, Cheek L, Ball J. Statistics review 13 : Receiver operating characteristic curves. Crit Care. 2004;8(6):508-12.

16. Ho PS, Goo JM, Jo CH. Receiver operating characteristic (ROC) curve: practical review for radiologists. Korean J Radiol. 2004;5(1):11-8.

17. Jaiswal M, Bansal R, Agarwal A. Role of mid-upper arm circumference for determining overweight and obesity in children and adolescents. J Clin Diagnostic Res. 2017;11(8):SC05-8.

18. Van Tonder E, Mace L, Steenkamp L, TydemanEdwards R, Gerber K, Friskin D. Mid-upper arm circumference (MUAC) as a feasible tool in detecting adult malnutrition. South African J Clin Nutr. 2019;32(4):93-98.

19. Powell-Tuck J, Hennessy EM. A comparison of mid upper arm circumference, body mass index and weight loss as indices of undernutrition in acutely hospitalized patients. Clin Nutr. 2003;22(3):307-12.

20. Goswami AK, Kalaivani M, Gupta SK, Nongkynrih B,
Pandav CS. Usefulness of mid-upper arm circumference in assessment of nutritional status of elderly persons in Urban India. Int J Med Public Heal. 2018;8(1):34-7.

21. Sultana T, Karim MN, Ahmed T, Hossain MI. Assessment of undernutrition of Bangladeshi adults using anthropometry: Can body mass index be replaced by mid-upper-arm-circumference? PLoS One. 2015;10(4): e0121456.

22. Das P, Khatun A, Bose K, Chakraborty R. The validity of mid-upper arm circumference as an indicator of low BMI in population screening for undernutrition : a study among adult slum dwellers in eastern India. Public Health Nutr. 2018;21(14):2575-83.

23. Thorup L, Hamann SA, Kallestrup P, Hjortdal VE, Tripathee A, Neupane D, et al. Mid-upper arm circumference as an indicator of underweight in adults: a cross-sectional study from Nepal. BMC Public Health. 2020;20(1):1-7.

24. Barosa R, Roque Ramos L, Santos CA, Pereira M, Fonseca J. Mid upper arm circumference and PowellTuck and Hennessy's equation correlate with body mass index and can be used sequentially in gastrostomy fed patients. Clin Nutr. 2018;37(5):1584-8.

25. Nguyen P, Ramakrishnan U, Katz B, GonzalezCasanova I, Lowe AE, Nguyen H, et al. Mid-upper-arm and calf circumferences are useful predictors of underweight in women of reproductive age in northern Vietnam. Food Nutr Bull. 2014;35(3):301-11. 